\title{
STUDI KRITIS TERHADAP PEMIKIRAN HAJI MUHAMMAD SARNI ALABIO TENTANG ZAKAT DALAM KITAB MABA'ID ILMU FIKIH
}

\author{
Firqah Annajiyah Mansyuroh \\ Pascasarjana UIN Antasari Banjarmasin \\ firqahannajiyahmansyuroh@gmail.com \\ Diterima 22-03-2020 | Direview 15-05-2020 | Diterbitkan 22-06-2020
}

\begin{abstract}
:
This title of this article is An Analysis of Critical Thought Haji Muhammad Sarni Alabio Concerning Zakat in Maba'id of Jurisprudence (Maba'id Ilmu Fikih). The purpose of this article was to assess the Haji Mubammad Sarni Alabio thinking about the establishment of zakat, legal istinbath methods used, the reason of his thought, as well as the relevance of thought Sarni the context of zakat in Melayu world and Indonesia. The results of the article showed that there are three important thoughts about zakat that are explained in the Maba'id of Jurisprudence which we can critically analyze as a criticism the extent to which the figh of zakat is relevant as applied science both past and present. First, the book only mentions zakat for plants and fruits by only mention the 10\% without the 5\%. Second, only plants that produce staples, dates and dried grapes, gold and silver are required to pay zakat. Third, the unclear nisab of gold and silver. Law istinbath method used is based on Mazhab Syafi'i but without a clear nash mention on the book. Maba'id of Jurisprudence. The Maba'id of Jurisprudence is a work of Malay Jurisprudence that needs to be appreciated. However, in order to be relevantly studied, there should be editors who provide explanations of contemporary fiqh zakat.
\end{abstract}

Key word: Malay Figh, Zakat, Sarni Alabio

\begin{abstract}
Abstrak:
Judul tulisan ini adalab Studi Kritis Terhadap Pemikiran Haji Muhammad Sarni Alabio Tentang Zakat dalam Kitab Maba'id Ilmu Fikih. Tujuan artikel ini adalah untuk menilai pemikiran Haji Mubammad Sarni Alabio tentang pembentukan zakat, metode istinbath bukum yang digunakan, alasan pemikirannya, serta relevansi pemikiran Sarni dalam konteks zakat di dunia Melayu dan Indonesia. Hasil penelitian ini menunjukean babwa ada tiga pemikiran penting Sarni tentang zakat yang dijelaskan dalam Maba'id Ilmu Fikih yang dapat kita analisis secara kritis sebagai kritik sejauh mana fikih zakat relevan sebagai ilmu terapan baik dulu dan sekarang. Pertama, kitab ini
\end{abstract}


hanya menyebutkan zakat untuk tanaman dan buah-buaban dengan hanya menyebutkan bagian 10\% tanpa 5\%. Kedua, hanya tanaman yang menghasilkan bahan pokok, kurma dan anggur kering, emas dan perak yang dibaruskan membayar zakat. Ketiga, nisab emas dan perak yang tidak jelas. Metode bukum istinbath yang digunakan didasarkan pada Maz̧hab Syafi'i tetapi tanpa menyebutkan nash secara jelas pada buku Maba'id Ilmu Fikib. Kitab ini adalab karya Fikih Melayu yang perlu dibargai. Namun, agar dapat dipelajari secara relevan, harus ada editor yang memberikan penjelasan tentang rakat fikib kontemporer.

Kata Kunci: Fikib Melayu, Zakat, Sarni Alabio

\section{Pendahuluan}

Di antara tujuan utama dan pertama dalam suatu masyarakat di dunia ini ialah menghendaki kehidupan yang sejahtera dan bahagia. Dalam tradisi masyarakat Muslim, kebahagiaan hidup adalah kebahagiaan dunia dan akhirat. Untuk mencapai itu Islam telah meletakkan kerangka dasar bangunan perekonomian dan sistem keuangan yang sistemik. Bangunan kokoh ekonomi dan keuangan yang dimaksud salah satunya adalah melalui zakat, yang disyariatkan sejak tahun kedua Hijrah. ${ }^{1}$

Dari tahun ke tahun para ulama menyebarkan fikih zakat disegala penjuru nusantara, tidak tertinggal pula di daerah Kalimantan Selatan. Pada abad ke-20 muncul sejumlah ulama Banjar yang karya intelektualnya sering menjadi referensi intelektual, baik di pengajian maupun di pesantren, salah satunya adalah Haji Muhammad Sarni Alabio melalui karyanya Maba’id Ilmu Fikih. $^{2}$

Penulisan Maba'id Ilmu Fikih, sebagaimana diakui sendiri oleh Haji Muhammad Sarni Alabio, dilatarbelakangi oleh keinginan agar masyarakat dapat mengambil pelajaran dan mengamalkan tidak hanya fikih ibadah namun juga fikih muamalah yang hubungannya adalah hubungan sosial antar manusia. Kitab ini menurutnya adalah kitab terapan yang diambil dari rujukan kitab Irsyadul Anam karya Habib Usman bin Yahya, seorang mufti Betawi.

Mengingat adanya pengakuan Haji Muhammad Sarni Alabio itu, maka perlu diadakan analisis kritis untuk mengetahui seberapa jauh keterkaitan

\footnotetext{
${ }^{1}$ Muhammad Amin Suma, "Zakat, Infak, Dan Sedekah: Modal Dan Model Ideal Pembangunan Ekonomi Dan Keuangan Modern," Al-Iqtishad V 2 (2013): 253-74.

2 Rahmadi, "Dinamika Intelektual Islam Di Kalimantan Selatan: Studi Genealogi, Referensi, Dan Produk Pemikiran," Imu Ushuluddin 111 (2012): 1-19.
} 
pemikiran Al-Alabio tentang zakat yang terdapat dalam kitab Maba'id Ilmu Fikih dengan kitab referensi yang disebutkan itu. Serta analisis kritis sejauh mana fikih zakatnya relevan sebagai ilmu terapan baik masa lalu maupun masa sekarang, yang penulis tulis menjadi Studi Kritis Terhadap Pemikiran Haji Muhammad Sarni Alabio Tentang Zakat dalam Kitab Maba'id Ilmu Fikih.

\section{Identitas Haji Muhammad Sarni Alabio}

Nama lengkap penyusun kitab Maba'id Ilmu Fikih ini adalah Haji Muhammad Sarni bin Haji Jarmani bin Haji Muhammad Siddiq. Dia dilahirkan pada tahun 1915 di desa Sungai Tabukan Alabio. Tanggal lahirnya tidak diketahui secara pasti namun diketahui dia meninggal pada malam Jum'at, tanggal 8 Zulhijjah 1408 Hijriah, bertepatan dengan 6 Maret 1988 Masehi di Alabio dalam usia sekitar 73 tahun. Haji Muhammad Sarni terlahir dari pasangan Haji Jarmani dan Hajah Rafi'ah. Dia dipelihara dan dibesarkan dalam lingkungan keluarga yang taat beragama. ${ }^{3}$

Ayahnya yaitu Haji Jarmani adalah salah seorang pemuka agama di kampungnya pada waktu itu. Dia cukup disiplin dalam mendidik dan menanamkan ilmu agama kepada putranya. Oleh karena itulah, sejak kanak kanak Muhammad Sarni sudah belajar membaca Alquran dan pelajaran agama, seperti tauhid dan fikih. Ia juga mempelajari ilmu nahwu atau qawa'id sebagai ilmu alat untuk mampu membaca dan memahami kitab-kitab yang berbahasa Arab. ${ }^{4}$

Selain belajar di rumah, dia juga dimasukkan oleh orang tuanya ke Sekolah Rakyat (SR). Di Sekolah Rakyat dia belajar selama enam tahun dan kemudian dia memasuki Normal Islam di Rantau. Dia menyelesaikan pendidikan di Rantau dalam beberapa tahun. Setelah itu dia melanjutkan belajar agama, khususnya ilmu tasawuf dari Haji Abdullah Masri di Amuntai. ${ }^{5}$

Haji Muhammad Sarni mempunyai tiga orang isteri yang masingmasing dikaruniai beberapa orang anak. Isteri pertamanya bernama Masriah, dari isterinya ini dia memperoleh enam orang anak, yaitu Riabi'ah, Ramlah, Abdul Latif, Fatinah, 'Asimah, dan Mahmudah. Isteri keduanya bernama Hajah Masrufah, dari isterinya ini dia memperoleh sembilan orang anak, yaitu; Drs. Haji Rusdi Halim, Norhidayah, Abdul Wahab, Ibrahim, Abdan Sakura, S. Ag.,

\footnotetext{
${ }^{3}$ Akhmad Khairudin dkk, Perkembangan Pemikiran Tasawuf Di Kalimantan Selatan (Banjarmasin: IAIN Antasari Press, 2014). hlm 169

${ }^{4}$ Khairudin dkk. hlm 169

${ }^{5}$ Khairudin dkk.hlm 170
} 
Abdul Wahid (alm.), Musleh (alm.), dan Liamdah (alm.). Isteri ketiganya bernama Khadijah, dari perkawinannya dengan isterinya yang terakhir ini dia memperoleh seorang putri bernama Muflihah. ${ }^{6}$

Adapun pekerjaannya sehari-hari adalah bertani di kampungnya. Selain bertani, dia juga memberikan pelajaran agama di rumahnya sendiri. Kegiatan ini berlangsung sejak tahun 1958 sampai akhir hayatnya pada tahun 1988. Peserta pengajiannya cukup banyak, karena materi pelajaran yang dia berikan juga beragam, mulai membaca Alquran dan tajwidnya, ilmu nahwu dan tasrif, fikih, tauhid, dan sampai pada ilmu tasawuf. Selain mengadakan pengajian di rumahnya sendiri, dia juga sering menyampaikan ceramah agama pada majelis taklim yang diselenggarakan oleh masyarakat setempat. Selain itu dia juga sering diminta menyampaikan ceramah agama dalam rangka peringatan Maulid Nabi Muhammad, Isra dan Mi'rajnya, dan atau acara-acara keagamaan lainnya. ${ }^{7}$

Kegiatan mengajar agama, selain di kampung halamannya sendiri, dia juga diminta mengajar tasawuf di daerah lain, antara lain di Sampit Kalimantan Tengah, yaitu di sebuah mesjid selama kurang lebih lima tahun, antara tahun 1955 dan 1960. Kemudian pada tahun 1973, dia diminta mengajar tasawuf di sebuah mesjid di Tamban selama enam bulan. Pekerjaan lainnya adalah sebagai Pembantu Petugas Pencatat Nikah, Talak, Cerai dan Rujuk (P3NTCR) yang lebih dikenal dengan sebutan penghulu (pangulu).Tugas sebagai penghulu ini dilaksanakan dari tahun 1960 sampai dengan tahun 1971. Pekerjaan sebagai penghulu inilah yang membuat Haji Muhammad Sarni lebih dikenal oleh masyarakat luas sampai akhir hayatnya. ${ }^{8}$

Haji Muhammad Sarni menunaikan ibadah haji (haji turis) yang didanai oleh Haji Jakfar, pemilik Hotel Berlin pada tahun 1976, dan sempat bermukim di Mekkah Al-Mukarramah selama enam bulan. ${ }^{9}$

Haji Muhammad Sarni merupakan seorang ulama yang tergolong kreatif dan produktif dalam berkarya tulis. Dalam berdakwah dan mengembangkan ilmu agama, dia tidak hanya menyampaikan secara lisan, namun dia juga melakukannya lewat karya-karya tulisnya sebagai buku pelajaran. Walaupun sebagian besar karyanya merupakan saduran atau ringkasan atas kitab-kitab ulama terdahulu, hal ini merupakan suatu

\footnotetext{
${ }^{6}$ Khairudin dkk. hlm 170

${ }^{7}$ Khairudin dkk. hlm 160-170

${ }^{8}$ Khairudin dkk. hlm 171

${ }^{9}$ Khairudin dkk. hlm 171
} 
kelebihannya dibanding dengan ulama-ulama lainnya yang tidak menghasilkan karya tulis mereka. ${ }^{10}$

Karya-karyanya sesuai bidang ilmu keislaman adalah sebagai berikut: Bidang Tauhid yaitu: Tubfabal-Ikbwin dan Hidayahal Mubtadiir. Bidang Fikih yaitu: Mabadi Tlm al-Figh jilid 1, 2, dan 3. Di bidang Tasawuf, yaitu: Mabadi ilm At-Tasawnuf, Al-Babjah Al-Mardiyyabfi Akblaqad-Diniyyah, dan Tubfah Ar-Ragibin jilid 1 dan 2, Futuh Al-Afifin jilid 1 dan 2. Karya tulisnya yang lain berupa buku Pelajaran Nahwu, Pelajaran Saraf, Pelajaran Tajwid, dan Penuntun Cara Berhilah. $^{11}$

Buku-buku tersebut semula ditulis dengan tulisan Arab Melayu oleh salah seorang muridnya yaitu Haji Muhammad Husaini, kemudian diperbanyak sesuai dengan keperluan. Dalam perkembangan berikutnya, buku-buku tersebut, khususnya yang berkaitan dengan Tauhid, Fikih, dan Tasawuf banyak digunakan oleh masyarakat dalam majelis taklim atau forum-forum pengajian agama. Hal ini membuat permintaan terhadap buku-buku tersebut semakin meningkat dan akhirnya diupayakan untuk digandakan dalam bentuk cetakan. Akhirnya atas izin dari keluarga Haji Muhammad Sarni, buku-buku tersebut diterbitkan oleh Toko Buku Murni Banjarmasin. Semua buku tersebut mengalami cetak ulang, sementara buku-buku lainnya, tidak dicetak dan diterbitkan, hal ini disebabkan oleh kurangnya peminat. ${ }^{12}$

\section{Kitab Maba'id Ilmu Fikih}

Cetakan Kitab Maba’id Ilmu Fikih dapat dengan mudah didapatkan di toko-toko buku lokal yang ada di wilayah Kalimantan Selatan, khususnya Banjarmasin. Dengan harga 8000 Rupiah di tahun 2019 penulis sudah dapat membawa pulang kitab setebal 130 halaman tersebut. Kitab Maba'id Ilmu Fikih karya Haji Muhammad Sarni Alabio sebenarnya berjumlah tiga jilid, namun dicetak menjadi satu kitab yang masih utuh tulisan tangan Arab Melayu. Meski begitu cetakan kitab ini tidak tebal karena menggunakan kertas buram atau HSSD (Hybrid Super Standard) yang biasa dipakai untuk percetakan buku murah atau kertas untuk coretan yang biasa digunakan untuk ujian hitungan seperti matematika. Cetakan yang penulis dapat adalah cetakan ketiga pada tahun 1404 Hijriah atau 1984 Masehi.

\footnotetext{
${ }^{10}$ Khairudin dkk. hlm 171

${ }^{11}$ Khairudin dkk. hlm 172

12 Khairudin dkk. Hlm 172
} 
Kitab yang ditulis dengan tulisan Arab Melayu ini didahului oleh dua pengantar dari guru Haji Muhammad Sarni Alabio yaitu Haji Sabran Pandulangan dan Haji Zuhri Mahfudz. Haji Sabran Pandulangan mengatakan:

"Maka setelah hamba perhatikan akan isi kitab ini 'Maba'id Ilmu Fikih' atas mazhab Syafi'i, disusun oleb salah seorang murid bamba yang sungguh dan rajin dalam meluaskan ilmu pengetabuan agama. Maka hamba dapati di dalam kitab tersebut adalah semua fikih bagi yang hak, baik sekali dipelajari.",'3

Kemudian Haji Muhammad Sarni Alabio menyatakan dalam pendahuluan jilid pertama mengenai latar belakang atau alasan penulisan kitab Maba'id Ilmu Fikih serta rujukan dalam kitab tersebut, dia menyebutkan: "Maka oleh karena berbubung dengan keadaan para penduduk di kampung saya Sungai Tabukan mulai ingin belajar ilmu fikih, ilmu yang wajib dipelajari dalam agama, dan setelah saya cari, kitab apa yang patut diajarkan yang sesuai dengan pabam mereka, dan saya dapati ialah 'Trsyadul Anam' karangan ulama Sayyid Usman Betawi ${ }^{14}$, tetapi oleh karena babasanya memakai bahasa Melayu Betawi banyak tiada dimengerti. Maka saya usabakan menyusun risalah ini, yang hampir sama isinya dengan kitab tersebut. Saya ambil dari bermacam-macam kitab bahasa Arab dan Melayu. Mudah-mudahan memberi faidah bagi siapa yang ingin membacanya."

Jilid pertama adalah edisi kedua yang ditulis pada 16 Jumadil Akhir tahun 1373 Hijriah atau 20 Februari 1954 Masehi. Pada jilid pertama Kitab Maba'id Ilmu Fikih hanya terdapat dua bagian yang berjumlah 42 halaman, yaitu Bab Bersuci (Thoharoh) 9 halaman dan Bab Salat (Sembahyang) sisanya. ${ }^{16}$

Jilid kedua juga merupakan edisi kedua yang ditulis pada 7 Jumadil Akhir 1392 Hijriah atau 18 Juli 1972 Masehi. Pada jilid kedua ini terdapat 4 bagian yang berjumlah 44 halaman, yaitu Bab Zakat, Bab Puasa, Bab Haji dan Bab Muamalah. ${ }^{17}$

\footnotetext{
${ }^{13}$ Haji Muhammad Sarni Alabio, Maba’id Ilmu Fikib 1, 2nd ed., 1 (Banjarmasin: Toko Buku Murni, 1984). hlm 3

${ }^{14}$ Jakarta Tourism, "Habib Usman Bin Adullah Bin Yahya," in Ensiklopedia jakarta Habib Usman Bin Adullab Bin Yabya, 2018, http:/ / encyclopedia.jakarta-tourism.go.id/post/HabibUsman-bin-Adullah-bin-Yahya?lang=id.

${ }^{15}$ Alabio, Maba'id Ilmu Fikih 1. hlm 4

16 Alabio.

${ }^{17}$ Haji Muhammad Sarni Alabio, Maba’id Ilmu Fikih 2, 2nd ed., 2 (Banjarmasin: Toko Buku Murni, 1984).
} 
Jilid ketiga merupakan edisi pertama yang ditulis pada 4 Syaban 1372 Hijriah atau 18 April 1953 Masehi. Jilid terakhir ini merupakan jilid yang paling banyak memuat bagian yaitu Bab Faraid (Warisan), Bab Wasiat, Bab Nikah, Bab Nafkah, Bab Jinayat, Bab Hudud, Bab Jihad, Bab Iman dan Nadzar, Bab Aqdhiyah dan Syahadah, serta yang terakhir adalah Bab mengenai memerdekakan budak atau Al-itqi. ${ }^{18}$ Kitab Maba'id Ilmu Fikih karya Haji Muhammad Sarni Alabio memang tidak membahas semua masalah fikih, tetapi juga tidak terbatas hanya membahas bidang ibadah semata. Hal-hal yang dibahas oleh Haji Muhammad Sarni Alabio dalam kitabnya itu memang cukup luas namun tidak mendalam, kitab ini dibuat ringkas dan bab-bab yang terkandung didalamnya adalah bab terapan. Hal ini mengindikasikan bahwa dengan Maba’id Ilmu Fikih, Haji Muhammad Sarni Alabio sangat besar kemauannya untuk memberikan pelajaran ilmu fikih yang bisa langsung diterapkan kepada masyarakatnya.

Di dalam kata pengantar jilid kedua Haji Muhammad Sarni Alabio mengatakan:

"Maka oleh karena buku pertama telah selesai dipelajarkan, saya usahakan pula menyusun buku kedua ini. Di buku pertama telah dinyatakan dari bal bersuci, sembabyang, dan apa yang bersangkutan dengannya. Maka buku kedua akan saya terangkan dari hal rakat, puasa, haji, dan bab muamalah, yaitu keperluan tiap-tiap yang bidup diatas dunia ini seperti jual-beli, sanda, pinjam, dan sebagainya. Segala apa yang kita usahakan di dalam dunia ini semuanya ada aturannya di dalam agama Islam. Maka tiap-tiap kita orang Islam bendaklah menuruti agama kita.

Sebagai pengharapan saya mudab-mudahan kiranya segala guru-guru agama selalu menerangkan selain dari pada bab ibadah, juga bab muamalah dan jika bukunya belum didapat yang sesuai dengan orang yang baru belajar, semoga buku ini dapat dipergunakan untuk dipelajari bagi mereka.",19

Berikut adalah peta konsep kitab Maba'id Ilmu Fikih karya Haji Muhammad Sarni Alabio.

\footnotetext{
${ }^{18}$ Haji Muhammad Sarni Alabio, Maba’id Ilmu Fikih 3, 1st ed., 3 (Banjarmasin: Toko Buku Murni, 1984).

${ }^{19}$ Alabio, Maba'id Ilmu Fikih 2.hlm 3
} 


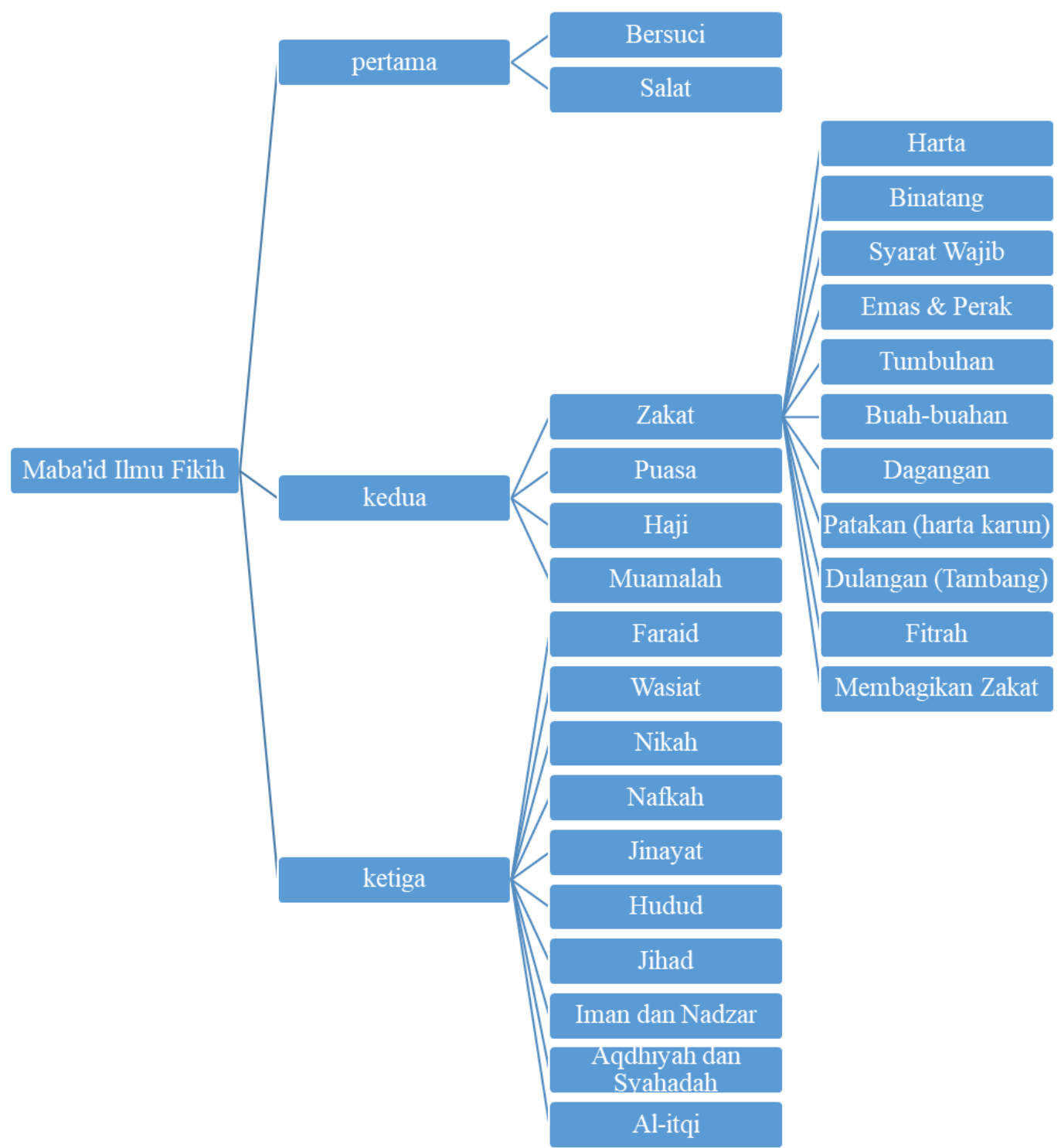

Gambar 1.1. Peta Konsep Kitab Maba'id Ilmu Fikih 


\section{Metode}

Metode penelitian dalam artikel ini menggunakan metode diskriptif untuk menilai pemikiran Haji Muhammad Sarni Alabio tentang pembentukan zakat, metode istinbath hukum yang digunakan, alasan pemikirannya, serta relevansi pemikiran Sarni dalam konteks zakat di dunia Melayu dan Indonesia.

\section{Studi Kritis Zakat dalam Maba'id Ilmu Fikih Haji Muhammad Sarni} Alabio

Ada tiga pemikiran penting tentang zakat yang terdapat dalam Kitab Maba'id Ilmu Fikih yang perlu dikemukakan di sini dan sekaligus menganalisisnya dengan studi kritis. Sebagaimana disebutkan sendiri oleh penulisnya, bahwa ketika menyusun kitab Maba'id Ilmu Fikih ia berlandasan pada kitab dari madzhab Syafi'i khususnya Irsyad Anam karya Habib Usman bin Yahya Betawi dan kitab-kitab lain yang tidak disebutkan secara eksplisit oleh Haji Muhammad Sarni sebagai rujukan.

Pemikiran pertama adalah tentang zakat tumbuh-tumbuhan dan buahbuahan, yakni tentang kadar zakat yang dikeluarkan dan objek tidak wajib zakat kecuali pada tumbuhan yang dijadikan makanan pokok, buah kurma, dan anggur kering. Dalam Maba'id Ilmu Fikih ditegaskan bahwa selain padi, gandum, jagung, kacang, buah kurma dan anggur kering maka tidak dikeluarkan zakatnya. Ia menyatakan,

"Tumbub-tumbuban yang diwajibkan zakat ialab yang hasilnya dijadikan makanan kehidupan tiap-tiap hari seperti padi di negeri kita ini atau gandum, jagung, kacang di lain-lain negeri. Maka mula-mula nisabnya yaitu 5 (lima) wisiq yaitu 300 gantang fitrah yang bersih dari pada kulat. Adapun padi maka nisabnya dua kali itu yaitu kira-kira 85 blek miyang ka tanab. Maka dikeluarkan zakatnya sepersepulub bahagian. Buab-buahan yang diwajibkan zakat ialah kurma dan anggur kering. Maka nisab dan zakatnya seperti tersebut pada zakat tumbubtumbuban juga."20

\footnotetext{
${ }^{20}$ Alabio. hlm 7
} 
Dengan penyebutan ini maka Haji Muhammad Sarni Alabio memberi kepastian hukum bagi masyarakat Banjar bahwa zakat tumbuhan dan buahbuahan adalah sebesar $10 \%$ dan bagi mereka yang memiliki kebun selain menghasikan yang telah disebutkan, meskipun dalam jumlah yang bila dianalogikan dengan harga sudah mencapai nisab, tidak wajib zakat.

Dalam Maba'id Ilmu Fikih hanya menyebutkan satu bagian zakat tumbuhan dan buah-buahan yang dikeluarkan yaitu 10\%. Padahal di kitab yang penulisnya sebut sebagai rujukan yaitu karya Habib Usman bin Yahya menyebutkan dua kategori bagian zakat yaitu,

"Bagi tumbuhan yang airnya didapat dengan tidak memerlukan usaba/ disiram, yang wajib dikeluarkan yaitu satu bahagian daripada sepuluh bahagian, atau yang disebut usyur (sepersepulub nya atau sepuluh persen) Sedangkan jikalau tumbuhannya dengan disiram atau memerlukan ongkos (biaya) untuk membeli air maka zakatnya adalah didalam duapulub bahagian dikeluarkan satu bagian, atau yang disebut nisful usyur (seperduapulub atau lima persen)"21

Meski dalam Irsyadul Anam tidak disebutkan dalilnya, tetapi penulis merujuk kepada hadis Nabi dari Ibnu Umar, Rasulullah shallallabu 'alaibi wa sallam bersabda,

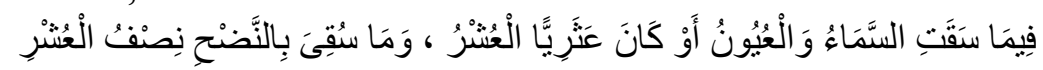

"Tanaman yang diairi dengan air bujan atau dengan mata air atau dengan air tadah bujan, maka dikenai zakat 1/10 (10\%). Sedangkan tanaman yang diairi dengan mengeluarkan biaya, maka dikenai zakat 1/20 (5\%).” H.R. Bukbari no. $1483^{22}$ dan Muslim no. $981^{23}$.

Kemungkinan terbesar dari alasan Haji Muhammad Sarni Alabio hanya menuliskan satu macam yakni bagian zakat $10 \%$ adalah karena masyarakat Banjar, khususnya di kampung Alabio, hanya menggunakan pertanian tadah

\footnotetext{
${ }^{21}$ Habib Usman bin Abdullah bin 'Aqil bin Yahya Al-Alawi Al-Husaini, Irsyadul Anam Fi

Tarjamati Arkanil Islam., 2nd ed. (Kudus: Menara Kudus, n.d.). hlm 59

${ }^{22}$ Muhammad bin Ismail Al Bukhari, Shahih Bukhari, Second (Beirut: Dar Ibn Katsir, n.d.). hlm 361

${ }^{23}$ Muslim bin al Hajjaj bin Muslim bin Kausyaz al-Qusyairi An-Naisaburi, Shabih Muslim, Juz 2 (Dar Al Mughni, 1998). hlm 436
} 
hujan dan tidak mengeluarkan biaya atas perairan sawah dan kebunnya. Ini sangat dimungkinkan karena daerah Kalimantan Selatan, khususnya Alabio, adalah daerah sungai dan biasanya sawah-sawah mereka berada tidak jauh dari sumber air. Alabio berada di Kabupaten Hulu Sungai Utara yang memiliki luas wilayah $\pm 892,7 \mathrm{~km}^{2}$. Sebagian besar terdiri atas dataran rendah yang digenangi oleh lahan rawa baik yang tergenang secara monoton maupun yang tergenang secara periodik. Kurang lebih $570 \mathrm{~km}^{2}$ adalah merupakan lahan rawa. HSU tercatat memiliki hutan rawa seluas 29.711 ha, rumput rawa 22.768 ha dan danau seluas $1.800 \mathrm{ha}^{24}$

Sebagaimana alasan dari penulisan kitab Maba'id Ilmu Fikih yang menginginkan agar masyarakat yang belajar agama Islam segera mempraktikan apa yang telah dipelajari, maka Haji Muhammad Sarni Alabio mencoba mengambil dari ilmu fikih zakat tumbuhan hanya yang terjadi di masyarakat sekitarnya dan tidak menuliskan apa yang tidak dipakai, yaitu pengairan yang dibiayai.

Kemudian posisi pemikiran Sarni tentang tidak wajib zakat pada tumbuhan dan buah selain itu perlu diteliti pada kitab yang secara eksplisit disebutkan sebagai referensi. Kitab Irsyadul Anam menyebutkan yang diwajibkan mengeluarkan zakat buah-buahan adalah kurma dan kismis (anggur kering), adapun tumbuh-tumbuhan yang diwajibkan mengeluarkan zakatnya adalah tumbuh-tumbuhan yang dimakan untuk kehidupan seperti gandum, terigu, jagung dan padi, serta kacang-kacangan. ${ }^{25}$

Pendapat yang menyatakan bahwa selain yang disebut dalam Maba'id Ilmu Fikih dan referensinya, perlu didiskusikan lebih lanjut. Dalam kedua kitab tersebut baik Habib Usman dan Haji Sarni hanya menyebutkan perihal zakat tumbuhan dan buah-buahan secara ringkas dan tanpa dalil. Maka penulis mencoba menelusuri dalil dari Mazhab Syafi'i yang pengarang kitab sebutkan sebagai mazhab yang mereka pakai dalam penulisan kitab tersebut.

\footnotetext{
${ }^{24}$ Wikipedia Bahasa Indonesia, Ensiklopedia Bebas, "Kabupaten Hulu Sungai Utara," Kabupaten Hulu Sungai Utara (blog), accessed October 30, 2019, https://id.wikipedia.org/wiki/Kabupaten_Hulu_Sungai_Utara\#Iklim_dan_Curah_Hujan. 25 Al-Husaini, Irsyadul Anam Fi Tarjamati Arkanil Islam. hlm 59
} 
Penulis temukan dalam Sayid Sabiq bahwa Imam Syafi'i berpendapat, wajib zakat pada apa yang dihasilkan bumi dengan syarat merupakan makanan pokok dan dapat disimpan, serta ditanam oleh manusia seperti gandum dan padi. ${ }^{26} \mathrm{Hal}$ ini dikarenakan pada masa Rasulullah, zakat dipungut dari gandum, padi, kurma, dan anggur kering.

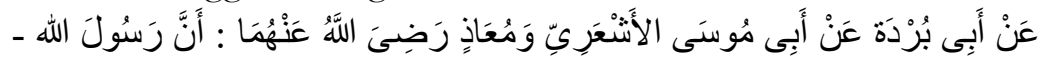

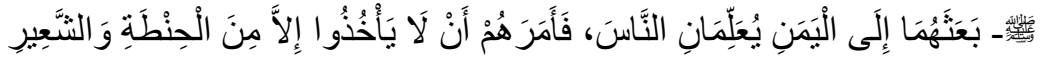

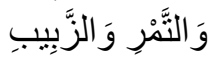

'Dari Abu Burdab, bahwa Abu Musa Al-Asy'ari dan Mu'adz, bin Jabal radbiallahu 'anbuma pernah diutus ke Yaman untuk mengajarkan perkara agama. Nabi shallallabu 'alaibi wa sallam memerintabkan mereka agar tidak mengambil zakat pertanian kecuali dari empat jenis tanaman: binthah (gandum halus), sya'ir (gandum kasar), kurma, dan zabib (kismis)."

H.R. Hakim 2: 32 dan Baihaqi 4: 125. ${ }^{27}$

Kemudian perkataan Musa bin Thalhah: "Ada keterangan dari Rasulullah mengenai lima macam: padi, gandum, padi sult, anggur kering dan kurma. Tapi hasil-hasil bumi lainnya tidak wajib zakat". Begitu pula Qurthubi yang menyatakan: "Zakat itu hanyalah pada makanan-makanan yang mengenyangi, bukan pada sayur-sayuran. Di Thaif banyak terdapat delima, persik, dan lain-lain, tapi tak ada keterangan bahwa Nabi Muhammad maupun salah seorang khalifahnya memungut zakat dari buah-buahan tersebut." 28

Dalam kitab Maba'id Ilmu Fikih disebutkan "tumbuh-tumbuhan yang diwajibkan zakat ialah yang hasilnya dijadikan makanan kehidupan tiap-tiap hari seperti padi di negeri kita ini atau gandum, jagung, kacang di lain-lain negeri. ${ }^{29}$ Meski tidak memberikan dalil dan alasan, namun jika kita kaji secara kritis analisis wacana yang terdapat pada Maba'id Ilmu Fikih maka zakat hasil pertanian tidak hanya terbatas pada komoditi yang disebukan dalam hadis tadi dengan alasan;

\footnotetext{
${ }^{26}$ Sayid Sabiq, Fikih Sunnah Jilid 3 (Bandung: PT Al-Ma'arif, 1978). hlm 45

${ }^{27}$ Sabiq. hlm 42

${ }^{28}$ Sabiq. hlm 44

${ }^{29}$ Alabio, Maba'id Ilmu Fikib 2. hlm 7
} 
1. Kita bisa beralasan dengan hadis Mu'adz dan pendapat Imam Qurthubi bahwa tidak ada zakat pada sayur-sayuran. Ini menunjukkan bahwa zakat hasil pertanian diambil dari tanaman yang bisa disimpan dalam waktu yang lama dan tidak mudah rusak. Sedangkan sayur-sayuran tidaklah memiliki sifat demikian.

2. Komoditi yang disebutkan dalam hadis adalah makanan pokok yang ada pada saat itu. Tidak mungkin ini hanya berlaku untuk makanan pokok seperti saat itu saja dan tidak berlaku untuk negeri lainnya karena syariat tidaklah membuat 'illah suatu hukum dengan nama semata namun dilihat dari sifat atau ciri-cirinya.

Pendapat dari Mazhab Imam Syafi'i lebih dicenderungi karena dalil tersebut memiliki 'illah (sebab hukum) yang dapat ditarik di mana gandum, kurma dan kismis adalah makanan pokok di masa silam di negeri tertentu (karena menjadi suatu kebutuhan primer) dan makanan tersebut bisa disimpan. Sehingga hal ini dapat diqiyaskan atau dianalogikan pada padi, gandum, jagung, kacang-kacangan yang memiliki 'illah yang sama.

Namun yang menjadi permasalahan kedua yaitu kitab Maba’id Ilmu Fikih membatasi hanya pada tumbuhan pangan, kurma dan anggur kering, padahal perubahan sektoral ekonomi tidak dapat dihindarkan. Ulama dituntut untuk mampu membuat produk hukum dan mampu merespon cepatnya perkembangan dan pertumbuhan ekonomi modern yang mempengaruhi pola perubahan pendapatan masyarakat di berbagai sektor. Perkembangan dan perubahan ini dapat dilihat dibeberapa sektor seperti pertanian (agrikultur) terjadi perubahan masif dari pola pertanian tradisional kepada pertanian industrial. Perubahan ini tentunya dapat memunculkan pola-pola baru dalam mendapatkan penghasilan kekayaan dari sektor ini. Apalagi dalam budaya konsumerisme, kebutuhan masyarakat bukan hanya untuk memenuhi kebutuhan primer, berbagai kebutuhan sekunder seolah-olah menjadi trend untuk dipenuhi sehingga di sektor ini tidak hanya berproduksi untuk memenuhi kebutuhan pangan tetapi juga non-pangan. ${ }^{30}$

\footnotetext{
${ }^{30}$ Imamul Hakim, "Diversifikasi Penghasilan Kontemporer Sebagai Alternatif Sumber Dana Zakat," Falah Jurnal Ekonomi Syariah 11 (2006): 103-12. hlm 110
} 
Sebagai contoh di wilayah-wilayah tertentu masyarakat cenderung menanam pohon jati di perkebunanannya karena pendapatannya lebih menjanjikan dan biaya perawatannya lebih kecil, selain itu, pemilik lahan adalah justru dari golongan mampu. Di wilayah Kalimantan sendiri sangat terkenal dengan industri perkebunan karet dan kelapa sawitnya. Ulama-ulama kontemporer seperti Yusuf Qardhawi ${ }^{31}$, Didin Hafidhuddinn ${ }^{32}$, serta dalam Undang-Undang Republik Indonesia Nomor 23 Tahun 2011 Tentang Pengelolaan Zakat mengakui adanya zakat industri pertanian, perkebunan, dan kehutanan. $^{33}$

Ini dikarenakan keumuman jenis tanaman dalam dalil Alquran surah Al-An'am/6: 141 yang berbunyi,

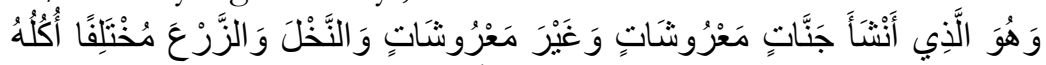

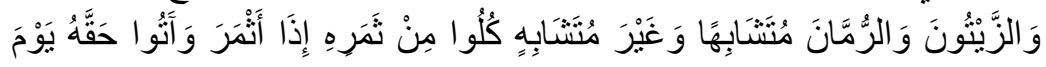
حَصَّادِهِ

"Dan Dialah yang menjadikan kebun-kebun yang berjunjung dan yang tidak berjunjung, pohon korma, tanam-tanaman yang bermacam-macam buabnya, zaitun dan delima yang serupa (bentuk dan warnanya) dan tidak sama (rasanya). Makanlab dari buahnya (yang bermacam-macam itu) bila dia berbuah, dan tunaikanlah haknya di hari memetik hasilnya (dengan disedekabkan kepada fakir miskin)." 34

Serta lafaz yang juga menyatakan umum dari sabda Nabi mengenai kadar zakat tumbuhan yaitu kata فِ فيَّا yang berarti pada apa-apa, atau pada apa juga, adalah kata umum yang meluaskan kepada apapun yang dihasilkan bumi ialah bertentangannya qiyas bahan pokok dengan keumuman lafaz. ${ }^{35}$

Masih dalam pemikiran Haji Muhammad Sarni Alabio tentang tidak wajib zakat, kali ini pada benda-benda berharga selain emas dan perak. Dengan penyebutan ini maka memberi kepastian hukum bagi masyarakat Banjar bahwa

\footnotetext{
${ }^{31}$ Yusuf Al Qardhawi, Hukum Zakat, 2nd ed (Bogor: Pustaka Litera, 1991).

${ }^{32}$ Didin Hafidhuddin, Zakat Dalam Perekonomian Modern (Jakarta: Gema Insani, 2002). hlm 120

${ }_{33}$ Presiden Republik Indonesia, Undang-Undang Republik Indonesia Nomor 23 Tabun 2011 Tentang Pengelolaan Zakat, 2011.

${ }^{34}$ Departemen Agama RI, Al-Qur'an Dan Terjemahannya (Semarang: Toha Putera, 1989).

${ }^{35}$ Sabiq, Fikib Sunnah Jilid 3. hlm 47
} 
memiliki intan, baru permata dan galian-galian tambang seperti batu bara dan mineral lainnya meskipun dalam jumlah yang bila dianalogkan dengan harga emas sudah mencapai nisab, tidak wajib zakat.

Dalam kitab Maba'id Ilmu Fikih Haji Muhammad Sarni Alabio menyatakan,

"Zakat patakan yaitu emas dan perak yang disimpan oleh orang yang dabulu sebelum Islam di dalam tanah maka jika mendapatkannya dan cukup nisabnya wajib dikeluarkan zakatnya dengan bersegera yaitu seperlima bahagian. Zakat dulangan yaitu emas dan perak yang di dalam tanah dari asal kejadiannya maka jika mendapatkannya dan cukup nisabnya wajib dikeluarkan zakatnya dengan bersegera pula yaitu sebahagian dari empatpulub bahagian. ${ }^{\prime 36}$

Posisi pemikiran Haji Muhammad Sarni Alabio tentang tidak wajib zakat pada benda-benda berharga selain emas dan perak itu perlu diteliti pada kitab yang secara eksplisit disebutkan dalam Maba'id Ilmu Fikih sebagai referensi yaitu Irsyadul Anam. Dalam pasal ke empatpuluh tujuh Zakat Rakaz / Harta Terpendam dan pasal ke empatpuluh delapan Zakat Ma'din di Kitab Irsyadul Anam menyebutkan,

"Harta terpendam daripada Mas dan Perak yang dipendam oleh orangorang dabulu sebelum Nabi Mubammad Sallallohu Alaibi Wasallam, jikea didapat harta itu dan cukup akan nishabnya, maka wajib dikeluarkan zakatnya dengan segera, yaitu Khumus (seperlima atau 20 persen) yakni satu bahagian dari lima bahagian. Zakat Ma'din yaitu zakat Mas dan Perak yang didapat dari dalam tanah menurut asal kejadiannya (dari hasil tambang). Maka apabila didapat daripadanya mencukupi nishabnya, wajib atasnya mengeluarkan zakatnya yaitu satu bahagian dari empatpuluh bahagian yakni rubu'ul asyro (seper empatpulub atau 2.5 persen). ${ }^{, 37}$

Dengan demikian, pendapat Haji Muhammad Sarni Alabio tentang tidak wajib zakat pada benda-benda selain emas dan perak itu sudah disebutkan

\footnotetext{
${ }^{36}$ Alabio, Maba'id Imu Fikih 2. hlm 7

${ }^{37}$ Al-Husaini, Irsyadul Anam Fi Tarjamati Arkanil Islam. hlm 60-61
} 
dalam kitab yang dijadikan referensi dalam penyusunan Maba'id Ilmu Fikih. Meski begitu tidak dijelaskan mengapa benda-benda lain selain emas dan perak tidak dimasukan kedalam objek yang dizakati. Penulis mencoba mencari pandangan-pandangan lain dari ulama klasik yang juga memiliki pemikiran yang sama. Kitab Minhaj Ath-Thalibin Imam Nawawi menyebutkan bahwa bendabenda permata selain emas dan perak seperti mutiara tidak wajib zakat. Kitab Mughni Al-Muhtaj karya As-Syarbini dan kitab Tuhfat Al-Muhtaj dari AlHaitami menyebutkan bahwa benda-benda berharga seperti mutiara, yaqut, zabarjad dan marjan tidak wajib zakat karena tidak ada dalil yang menunjukkan kewajiban zakat padanya di samping benda-benda itu disediakan untuk dipakai sebagai perhiasan seperti halnya binatang yang dipergunakan untuk bekerja. ${ }^{38}$

Pokok permasalahannya adalah apakah zakat itu termasuk dalam bidang ta'abbudi seperti halnya salat dan puasa atau tidak. Bila zakat itu termasuk dalam bidang ta'abbudi maka ketentuan yang sudah diatur oleh nash tidak boleh diubah di mana akal fikiran tidak memegang peranan yang penting. Ijtihad tidak berlaku di dalamnya karena kita tidak boleh mengubah, menambah atau mengurangi apa yang sudah ditentukan. Akan tetapi bila zakat itu tidak termasuk dalam bidang ta'abbudi maka akal pikiran dapat memegang peranan selama masih dalam jangkauan yang dapat diterima oleh akal yang sehat dan tidak menyimpang dari aturan yang telah ada; dan di sini ayat-ayat Alquran maupun hadis-hadis Nabi bersifat fleksibel dan elastis di dalam penjabarannya. ${ }^{39}$

Menurut pendapat ulama klasik harta yang wajib dikeluarkan zakatnya hanyalah meliputi empat jenis harta. Yaitu meliputi, harta perdagangan, hasil pertanian (tanam-tanaman, buah-buahan), hewan ternak, dan barang berharga (emas dan perak). Hal ini menurut Didin disebabkan keempat jenis harta itulah yang paling banyak beredar dikalangan masyarakat. ${ }^{40}$

Namun menurut pendapat ulama kontemporer seperti Yusuf Qardhawi setelah mempertimbangkan berbagai hal dan tuntutan kontemporer, harta yang

\footnotetext{
${ }^{38}$ Muslich Shabir, "Penelitian Pemikiran Syekh Muhammad Arsyad Al-Banjari Tentang Zakat Dalam Kitab Sabil Al-Muhtadin: Analisis Intertekstual," Analisa XVI 01 (2018): 1-18. hlm 9 ${ }^{39}$ Shabir.

${ }^{40}$ Hafidhuddin, Zakat Dalam Perekonomian Modern. hlm 28
} 
wajib di zakati adalah binatang ternak, emas dan perak, uang, perdagangan, pertanian, madu dan produksi hewani, barang tambang dan hasil laut, investasi pabrik dan gedung dan sejenisnya, pencarian dan profesi, saham dan obligasi. ${ }^{41}$

BAZIS DKI Jakarta menyebutkan empat prinsip bagi harta yang harus dikeluarkan zakatnya, yaitu:

1. Semua harta yang mengandung 'illat kesuburan atau berkembang, baik berkembang dengan sendirinya atau dikembangkan dengan jalan diternakkan atau diperdagangkan.

2. Semua jenis tumbuh-tumbuhan dan buah-buahan yang bernilai ekonomis.

3. Segala harta yang dikeluarkan dari perut bumi, baik yang berbentuk cair maupun yang berbentuk padat.

4. Segala penghasilan seperti gajih, honor dan uang jasa. ${ }^{42}$

Sedangkan fatwa secara khusus berkenaan sumber zakat kontemporer terdapat dalam Fatwa Majelis Ulama Indonesia (MUI) propinsi DKI Jakarta nomor 02 tahun 2000 Tentang Beberapa Jenis Harta Benda Yang Wajib Dizakati antara lain:

1. Adr-Drahab wa al- Fiddlah, yakni emas dan perak, termasuk batu permata, intan, berlian dan logam mulia;

2. Ats-Tsarwah al-Hayawaniah (kekayaan yang berupa hewan). Hal ini tidak terbatas pada onta, sapi (kerbau) dan kambing (domba), tetapi meliputi seluruh hewan yang halal diternakkan, termasuk ayam ternak, itik ternak, dan burung ternak yang diperdagangkan;

3. Ats-tsarwah az-ziro'iyyah (kekayaan hasil pertanian). Hal ini tidak terbatas pada padi, jagung, gandum, anggur dan korma saja, tetapi meliputi seluruh hasil pertanian yang bernialai ekonomis dan dapat diperdaganngkan. Seperti cengkeh, tebu dan palawija;

4. Ats-tsarwah at- tijariyah, meliputi seluruh barang-barangyang sah dan dapat diperdagangkan;

\footnotetext{
${ }^{41}$ Qardhawi, Hukum Zakat. hlm 167, 501

${ }^{42}$ Shabir, "Penelitian Pemikiran Syekh Muhammad Arsyad Al-Banjari Tentang Zakat Dalam Kitab Sabil Al-Muhtadin: Analisis Intertekstual.” hlm 10
} 
5. An-nuqud (mata uang/uang kertas). Seperti uang Rupiah, ringgit, dolar, riyal dan dinar. Termasuk uang simpanan, tabungan, deposito dan surat-surat berharga;

6. Al-muntajat al-hayawaniyah wa az-zira'iyyah (barang yang diproduksi/dihasilkan oleh hewan atau dari tumbuh-tumbuhan). Seperti susu, madu lebah, gula dan permen;

7. Ats-tsarwah al-ma'daniyah wa al-babriyah (kekayaan yang berupa hasil pertambangan dan hasil laut). Seperti minyak, mineral, batubara, ikan dan tambak udang;

8. Al-mustaghallat (kekayaan yang berupa hasil industry dan perusahaan). Seperti industri mobil, properti, tekstil, garmen, industry pariwisata, penyewaan hotel, losmen, motel, rumah, ruko dan sebagainya;

9. Kasb al-'amal wa al-minha al-burrah (gaji, honorarium, upah, komisi, uang jasa, hadiah dan sebagainya), yang lazim dikenal dengan zakat profesi; dan

10. Al-Asham wa as-Sanadat (Saham dan Promes/surat perjanjian utang). ${ }^{43}$

Hukum atau fikih zakat yang digunakan oleh masyarakat Indonesia hingga dewasa ini masih merupakan hasil karya mujtahid beberapa abad silam baik secara konseptual maupun praktiknya. Terlihat akan adanya kesenjangan jika kitab Maba'id Ilmu Fikih karya Haji Muhammad Sani Alabio diterapkan dalam kehidupan umat Islam di zaman modern yang ditandai dengan pesatnya perkembangan di berbagai bidang kehidupan. Kesenjangan itu terlihat pada konsep, persepsi dan pemahaman zakat yang umumnya seolah-olah dipahami zakat sebagai ibadah semata-mata (ibadah mabdlah) terlepas dari konteks sosial ekonomi, yang berdampak pada pelaksanaannya. Karena dipahami sebagai ibadah semata-mata maka sifatnya sangat individual, rigid dan formal, padahal hukum zakat semestinya fleksibel, kondusif dan ekomodatif, zakat selain bernuansa ibadah juga bernuansa muamalat (sosial) sebagaimana yang tertulis pada pendahuluan Jilid ke 2 Maba’id Ilmu Fikih.

\footnotetext{
${ }^{43}$ MUI Provinsi DKI Jakarta, "Fatwa Jenis-Jenis Harta Benda Yang Wajib Dizakati," Fatwa Jenis-Jenis Harta Benda Yang W ajib Dizakati (blog), accessed October 30, 2019, https://www.muidkijakarta.or.id/fatwa-jenis-jenis-harta-benda-yang-wajib-dizakati/.
} 
Pada sisi objek zakat juga dikenakan pada objek tertentu yang berkembang ketika fikih zakat dirumuskan, perkembangan bidang kehidupan secara komersial masa kini sungguh tidak tercover dengan aturan fikih yang ada, selain itu gambaran objek zakat masih bernuansa timur tengah. Sudah saatnya fikih zakat dimekarkan agar lebih kontekstual dan akomodatif yang dapat mengantisipasi dan menjangkau setiap perkembangan terutama pada kegiatan komersial. ${ }^{44}$

Yang ketiga sekaligus terakhir adalah posisi nisab zakat emas dan perak dalam Maba’id Ilmu Fikih yang penulis rasa sangat tidak jelas. Haji Muhammad Sarni Alabio menyatakan, "Zakat emas dan perak mula-mula nisab emas berat 20 mitsqal yaitu kira-kira berat 10 Rupiah, maka dikeluarkan zakatnya sebabagian dari empatpulub bahagian. Dan mula-mula nisab perak berat 200 dirbam atan kira-kira limapulub delapan setengah Rupiah (Rp. 58.5) maka dikeluarkan zakatnya itu seperti zakat. Adapun wang kertas maka diwajibkan zakat seperti wang perak juga dengan menilai harganya." ${ }^{\text {*5 }}$

Penulis mencoba menelaah rujukan kitab ini yaitu Irsyadul Anam yang menyatakan,

"Nisabnya zakat Mas adalah duapuluh misqal, yaitu berat tiga rial ditambah dengan setengah suku. Nisabnya zakat Perak adalab beratnya duaratus dirbam, yaitu limapuluh delapan Rupiah zaman sekarang ditambah setengah Rupiah. Yang wajib dikeluarkan daripada keduanya itu yaitu satu bahagian daripada empat puluh bagian, yaitu yang disebut rubu'ul asyro (seper empatpulub atau 2.5 persen), dan cukup setabun dari waktu memilikinya, maka wajib dikeluarkan zakatnya dan sebagaimana lebihnya Mas dan Perak itu daripada nisabnya, maka dikeluarkan zakatnya pula sekedarnya." $" * 6$

\footnotetext{
${ }^{44}$ Hakim, "Diversifikasi Penghasilan Kontemporer Sebagai Alternatif Sumber Dana Zakat." hlm 109

${ }^{45}$ Alabio, Maba'id Imu Fikih 2. hlm 6

46 Al-Husaini, Irsyadul Anam Fi Tarjamati Arkanil Islam. hlm 60
} 
Dapat dilihat bahwa dalam hal perak Haji Muhammad Sarni Alabio persis mengulang kata-kata dari Habib Usman bin Yahya yang menyatakan bahwa nisab perak 200 dirham atau Rp. 85.5 di zaman Habib Usman bin Yahya hidup. Padahal perbedaan zaman antara Haji Muhammad Sarni Alabio dan Habib Usman bin Yahya sangat jauh jaraknya. Habib Usman bin Yahya lahir pada tahun 1822 Masehi dan meninggal pada 1913 Masehi. Sedangkan Haji Muhammad Sarni Alabio lahir pada 1915 dan meninggal pada 1988 Masehi. Perbedaan keduanya hampir satu abad dan banyak hal terjadi di Indonesia umumnya, Banjarmasin khususnya, salah satu yang paling bersejarah adalah kemerdekaan Indonesia.

Pada akhir pendudukan Jepang dan masa awal kemerdekaan Republik Indonesia, keadaan ekonomi sangat kacau. Inflasi yang sangat tinggi, blokade ekonomi oleh Belanda untuk menutup pintu perdagangan luar negeri RI, kas negara kosong, dan akibat eksploitasi besar-besaran di masa penjajahan. Karena inflasi yang tinggi pada akhir tahun 1950-an hingga awal tahun 1960an, tidak ada koin yang dikeluarkan setelah tahun 1961, dan koin yang masih beredar tidak berharga. Rupiah baru dicetak sebagai usaha untuk mengurangi inflasi tahun $1965 .{ }^{47}$ Sehingga sangat tidak mungkin keadaan ekonomi pada masa Habib Usman bin Yahya sama seperti pada masa Haji Muhammad Sarni Alabio.

Kemudian pada zakat emas nisab kira-kira berat 10 Rupiah sungguh sangat tidak jelas. Apakah yang dimaksud adalah emas seberat koin 10 Rupiah pada tahun 60-70an atau emas seharga 10 Rupiah pada tahun 60-70an? Pada tahun 1968 harga emas berada pada angka Rp. 369/Gram. Pada tahun 1978 emas menjadi Rp. 2746/Gram. Artinya selama rentang waktu 10 tahun 19681978 saja emas naik sebesar $645 \%{ }^{48}$ Sehingga tidak mungkin yang dimaksud adalah emas seharga 10 Rupiah.

\footnotetext{
${ }^{47}$ Zulkarnain and Anisa Onifah, Keadaan Sosial Ekonomi Pasca Kemerdekaan Indonesia (Yogyakarta, 2008).

48 "Business and Entrepreneurship Free Education.," Business and Entrepreneurship Free Education. (blog), accessed October 30, 2019, http://geraidinar.com/88-sample-data-articles/gdarticles $/$ berita?start $=6$.
} 
Sedangkan koin 10 Rupiah terberat yaitu dalam Undang-Undang nomor 19 Tahun 1946 pasal 1 menyebutkan:

"Dengan tidak mengurangi peraturan yang akan ditetapkan selanjutnya dalam Undang-undang tentang Uang Republik Indonesia, maka sebagai dasar nilai ditentukan sepulub Rupiah uang Republik Indonesia sama dengan emas murni seberat lima Gram." ${ }^{49}$

Uang koin 10 Rupiah yang terberat yaitu 5 Gram emas tetap tidak mungkin menjadi nisab yang dimaksud. Sebagaimana yang telah disebutkan oleh BAZNAS Indonesia yaitu zakat emas dan perak ditunaikan jika seorang muzaki (orang yang menunaikan zakat) memiliki emas mencapai nisab senilai 85 gram atau perak dengan mencapai nisab 595 gram. ${ }^{50}$ Ketidakpastian hukum dalam nisab emas dan perak di kitab Maba'id Ilmu Fikih sangat terasa baik di tahun pembuatan kitab tersebut dan jika ingin diimplementasikan pada saat ini.

\section{Simpulan}

Melalui penelitian ini dapat disimpulkan bahwa :

1. Maba'id Ilmu Fikih adalah sebuah kitab fikih sebanyak 3 jilid yang ditulis dengan Arab Melayu oleh Haji Muhammad Sarni Alabio (w. 1988) pada tahun 1371-1392 H./1953-1972 M. Penulisan kitab itu antara lain dilatarbelakangi oleh suatu keinginan untuk memfasilitasi keadaan para penduduk di kampungnya mulai ingin belajar ilmu fikih Mazhab Syafi'i dan mengamalkannya. Kitab yang menjadi rujukan adalah Irsyadul Anam karangan ulama Sayyid Usman Betawi, yang ternyata hampir sama isinya dengan kitab tersebut.

2. Bila dicermati dengan seksama, ada tiga pemikiran penting tentang zakat yang dijelaskan dalam Maba'id Ilmu Fikih yang dapat kita analisis dengan kritis kritis sejauh mana fikih zakatnya relevan sebagai ilmu

\footnotetext{
${ }^{49}$ Kompasiana.com., "65 Tahun Oeang Republik, Rupiahku Semakin Rontok,” 65 Tabun Oeang Republik, Rupiabku Semakin Rontok - Kompasiana.Com. (blog), accessed October 30, 2019, https://www.kompasiana.com/edygune/550906eda33311c5462e3a83/65-tahun-oeangrepublik-rupiahku-semakin-rontok.

${ }^{50}$ Badan Amil Zakat Nasional Indonesia, "Zakat Emas Dan Perak," Zakat Emas dan Perak (blog), accessed October 30, 2019, https://baznas.go.id/id/zakat-emas.
} 
terapan baik masa lalu maupun masa sekarang. Pertama, dalam kitab tersebut hanya disebutkan zakat untuk tanaman dan buah-buahan sebesar 10\%. Kedua, hanya tanaman yang menghasilkan bahan pokok, kurma dan anggur kering, emas dan perak saja yang diwajibi zakat. Ketiga, ketidakjelasan nisab emas dan perak.

3. Pada simpulan ini peneliti mencoba untuk memberikan beberapa saran. Maba'id Ilmu Fikih adalah karya kitab fikih Melayu yang perlu diapresiasi. Namun agar dapat dipelajari secara relevan karena kitab ini masih diajarkan di sekolah-sekolah dan di pesantren-pesantren hendaknya ada editor yang memberikan penjelasan-penjelasan tanpa mengurangi rasa hormat kepada Haji Muhammad Sarni Alabio dan keluarga. Kepada para guru-guru agama yang mengajarkan kitab itu bisa sambil menjelaskan hukum zakat kontemporer serta ilmu ushul fikih sebagai alat pengambilan hukum.

\section{DAFTAR PUSTAKA}

Alabio, Haji Muhammad Sarni. Maba'id Ilmu Fikih 1. 2nd ed. 1. Banjarmasin: Toko Buku Murni, 1984. . Maba'id Imu Fikih 2. 2nd ed. 2. Banjarmasin: Toko Buku Murni, 1984. . Maba’id Ilmu Fikih 3. 1st ed. 3. Banjarmasin: Toko Buku Murni, 1984.

Al-Husaini, Habib Usman bin Abdullah bin 'Aqil bin Yahya Al-Alawi. Irsyadul Anam Fi Tarjamati Arkanil Islam. 2nd ed. Kudus: Menara Kudus, n.d.

An-Naisaburi, Muslim bin al Hajjaj bin Muslim bin Kausyaz al-Qusyairi. Shabih Muslim. Juz 2. Dar Al Mughni, 1998.

Badan Amil Zakat Nasional Indonesia. "Zakat Emas Dan Perak." Zakat Emas dan Perak (blog). Accessed October 30, 2019. https://baznas.go.id/id/zakat-emas.

Bukhari, Muhammad bin Ismail Al. Shabih Bukhari. Second. Beirut: Dar Ibn Katsir, n.d.

Business and Entrepreneurship Free Education. "Business and Entrepreneurship Free Education.” Accessed October 30, 2019. http://geraidinar.com/88-sample-data-articles/gdarticles/berita?start $=6$.

Departemen Agama RI. Al-Qur'an Dan Terjemabannya. Semarang: Toha Putera, 1989. 
Hafidhuddin, Didin. Zakat Dalam Perekonomian Modern. Jakarta: Gema Insani, 2002.

Hakim, Imamul. "Diversifikasi Penghasilan Kontemporer Sebagai Alternatif Sumber Dana Zakat." Falah Jurnal Ekonomi Syariah 11 (2006): 103-12.

Indonesia, Presiden Republik. Undang-Undang Republik Indonesia Nomor 23 Tabun 2011 Tentang Pengelolaan Zakat, 2011.

Khairudin dkk, Akhmad. Perkembangan Pemikiran Tasawuf Di Kalimantan Selatan. Banjarmasin: IAIN Antasari Press, 2014.

Kompasiana.com. "65 Tahun Oeang Republik, Rupiahku Semakin Rontok.” 65 Tabun Oeang Republik, Rupiabku Semakin Rontok - Kompasiana.Com. (blog). Accessed October 30, 2019. https://www.kompasiana.com/edygune/550906eda33311c5462e3a83/ 65-tahun-oeang-republik-rupiahku-semakin-rontok.

MUI Provinsi DKI Jakarta. "Fatwa Jenis-Jenis Harta Benda Yang Wajib Dizakati." Fatwa Jenis-Jenis Harta Benda Yang Wajib Dirakati (blog). Accessed October 30, 2019. https://www.muidkijakarta.or.id/fatwajenis-jenis-harta-benda-yang-wajib-dizakati/.

Qardhawi, Yusuf Al. Hukum Zakat. 2nd ed. Bogor: Pustaka Litera, 1991.

Rahmadi. "Dinamika Intelektual Islam Di Kalimantan Selatan: Studi Genealogi, Referensi, Dan Produk Pemikiran." Ilmu Ushuluddin 111 (2012): 1-19.

Sabiq, Sayid. Fikih Sunnah Jilid 3. Bandung: PT Al-Ma’arif, 1978.

Shabir, Muslich. "Penelitian Pemikiran Syekh Muhammad Arsyad Al-Banjari Tentang Zakat Dalam Kitab Sabil Al-Muhtadin: Analisis Intertekstual." Analisa XVI 01 (2018): 1-18.

Suma, Muhammad Amin. "Zakat, Infak, Dan Sedekah: Modal Dan Model Ideal Pembangunan Ekonomi Dan Keuangan Modern." Al-Iqtishad V 2 (2013): 253-74.

Tourism, Jakarta. "Habib Usman Bin Adullah Bin Yahya." In Ensiklopedia jakarta Habib Usman Bin Adullah Bin Yabya, 2018. http://encyclopedia.jakarta-tourism.go.id/post/Habib-Usman-binAdullah-bin-Yahya?lang=id.

Wikipedia Bahasa Indonesia, Ensiklopedia Bebas. "Kabupaten Hulu Sungai Utara." Kabupaten Hulu Sungai Utara (blog). Accessed October 30, 2019. https://id.wikipedia.org/wiki/Kabupaten_Hulu_Sungai_Utara\#Iklim_ dan_Curah_Hujan. 
Zulkarnain, and Anisa Onifah. Keadaan Sosial Ekonomi Pasca Kemerdekaan Indonesia. Yogyakarta, 2008. 